\title{
Stress-induced changes in miRNA biogenesis and functioning
}

\author{
Marta Olejniczak $^{1}$ - Anna Kotowska-Zimmer ${ }^{1} \cdot$ Wlodzimierz Krzyzosiak $^{1}$
}

Received: 5 May 2017 / Revised: 30 June 2017 / Accepted: 11 July 2017 / Published online: 17 July 2017

(C) The Author(s) 2017. This article is an open access publication

\begin{abstract}
MicroRNAs (miRNAs) are small, noncoding RNAs that play key roles in the regulation of cellular homeostasis in eukaryotic organisms. There is emerging evidence that some of these processes are influenced by various forms of cellular stresses, including DNA damage, pathogen invasion or chronic stress associated with diseases. Many reports over the last decade demonstrate examples of stress-induced miRNA deregulation at the level of transcription, processing, subcellular localization and functioning. Moreover, core miRNA biogenesis proteins and their interactions with partners can be selectively regulated in response to stress signaling. However, little is known about the role of isomiRs and the interactions of miRNA with non-canonical targets in the context of the stress response. In this review, we summarize the current knowledge on miRNA functions under various stresses, including chronic stress and miRNA deregulation in the pathogenesis of age-associated neurodegenerative disorders.
\end{abstract}

Keywords Inflammation - Neurodegeneration - Drosha · Alzheimer's disease · Parkinson's disease $\cdot$ Huntington's disease $\cdot$ ALS

Electronic supplementary material The online version of this article (doi:10.1007/s00018-017-2591-0) contains supplementary material, which is available to authorized users.

Marta Olejniczak

marta.olejniczak@ibch.poznan.pl

Wlodzimierz Krzyzosiak

wlodkrzy@ibch.poznan.pl

1 Department of Molecular Biomedicine, Institute of Bioorganic Chemistry, Polish Academy of Sciences, Noskowskiego 12/14, 61-704 Poznan, Poland

\section{Introduction}

Cellular stress can be defined as changes in the environment that significantly disturb cellular homeostasis and cause damage to macromolecules such as proteins, DNA, RNA and lipids. Cells respond to stress by activating mechanisms leading to the restoration of cellular homeostasis or adaptation to environmental conditions through growth arrest, repair or clearance of damaged macromolecules and changes in the gene expression programs. Moreover, excessive damage resulting from the high dose, time of exposition or potency of a stressor may trigger programmed cell death (apoptosis). There is growing evidence to confirm the critical role of non-coding RNAs, in particular miRNAs in cellular stress responses [1-4]. These short RNAs, approximately $22 \mathrm{nt}$ in length, control the expression of more than half of the protein-coding genes responsible for major cellular processes such as proliferation and cell cycle progression, differentiation, immune response and apoptosis [5]. miRNAs, post-transcriptional regulators of gene expression, offer the possibility of fast and economical regulation during stress by targeting multiple transcripts at the same time and without the need to synthesize proteins.

Cellular biogenesis of miRNAs is a multi-step process including the transcription of miRNA genes, mostly by RNA polymerase II, and generation of long primary transcripts (pri-miRNA) that are capped and polyadenylated $[6,7]$ (Fig. 1a). In the next step, pri-miRNAs are further processed in the nucleus by the microprocessor complex composed of the RNase III Drosha and its RNA-binding protein component, DiGeorge syndrome critical region 8 (DGCR8). Drosha can also interact with DEAD-box helicase (DDX) proteins: DDX5 (known as p68), DDX17 (known as p72) and DDX1 required for the biogenesis of some miRNAs. The emerging approximately $70 \mathrm{nt}$ in length miRNA 
a

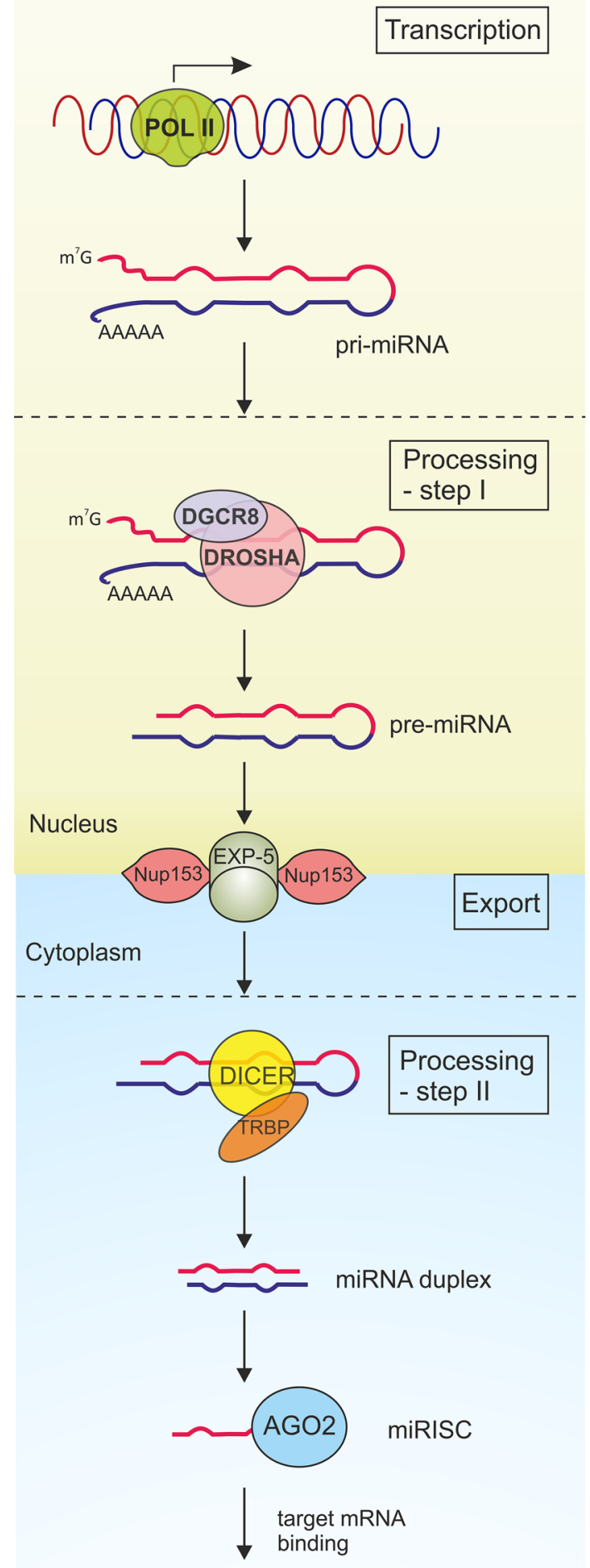

translation repression and mRNA degradation b DNA damage

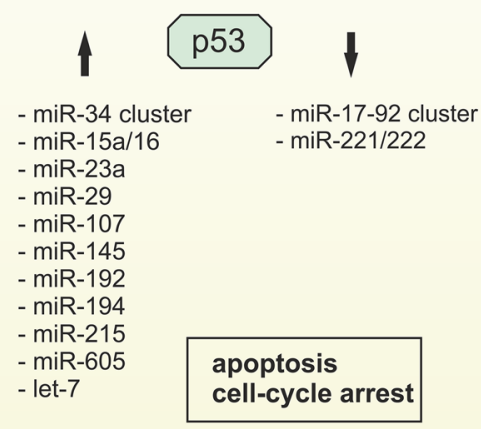

d $\uparrow$ pri-miRNA processing

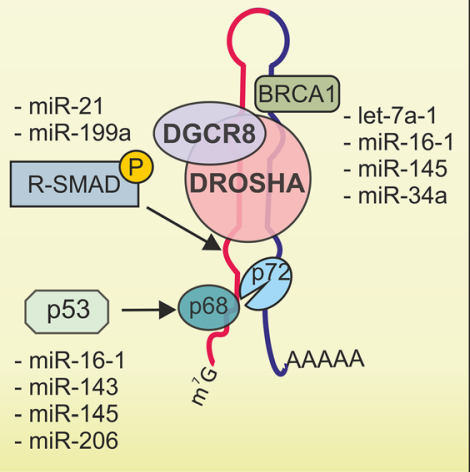

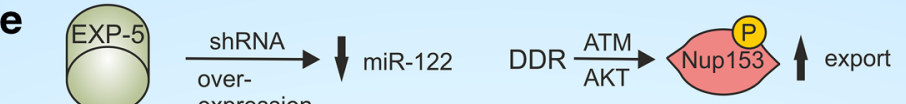

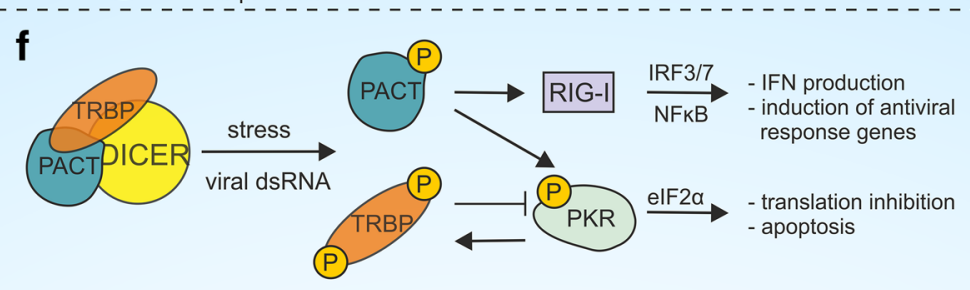

g

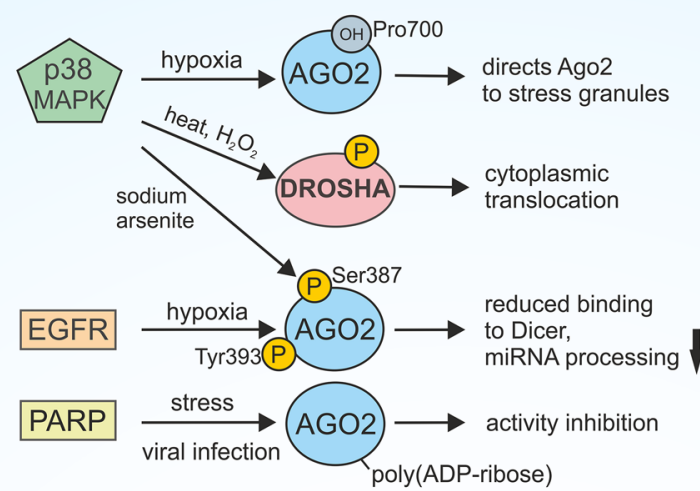


४Fig. 1 Stress-induced deregulation of miRNA biogenesis. a The biogenesis of miRNA begins with RNA polymerase II-dependent transcription that generates pri-miRNA. During the first processing step, pri-miRNAs are cropped to pre-miRNAs by the microprocessor complex composed of Drosha and DGCR8. Next, pre-miRNAs are transported from the nucleus to the cytoplasm by Exportin $-5 /$ RanGTP complex where they undergo processing by the RNase III protein-Dicer with the cofactor protein TRBP. Stem-loop structure of pre-miRNA is cleaved to the short miRNA duplex that is approximately $22 \mathrm{nt}$ in length. In the next step, the miRNA is incorporated into the RNA-induced silencing complex (RISC), and following unwinding and strand selection, the mature miRNA can recognize the target sequence that is localized mainly in the 3' UTRs of transcripts. Binding of the miRISC to the target results in translational repression and/or deadenylation and degradation. b, c Transcriptional deregulation of miRNA is triggered by various stresses that are responsible for activation of transcription factors such as p53 and $\mathrm{NF}-\kappa \mathrm{B}$. b Deregulation of miRNAs and their target genes results in cell-cycle arrest and apoptosis (p53-dependent signaling) or $\mathbf{c}$ influences survival and proliferation (NF- $\mathrm{KB}-$ dependent signaling). $\mathbf{d}$ The first step of miRNA processing is regulated by stress and results in enhanced or suppressed miRNA maturation. Upon stimulation, transcription factors, such as R-SMADs, p53 and BRCA1 facilitate the processing of some pri-miRNAs by direct pri-miRNA binding or stabilization of microprocessor complex. RNA-binding proteins, such as ADAR1, ADAR2, KSRP and DDX1 can also regulate pri-miRNA processing upon stress-conditions. Moreover, pri-miRNA processing may be suppressed during oxidative stress by heme oxygenase-1 (HMOX1)-mediated DGCR8 inhibition. e The export of premiRNA from the nucleus to the cytosol may be disturbed upon stress conditions. Exportin-5 (EXP-5) saturation by shRNA overexpression results in down-regulation of mature miR-122. Upon DNA damage, ATM-activated AKT kinase phosphorylates nucleopore component Nup153, thus enhancing its interaction with EXP-5 and promoting the export of pre-miRNAs into the cytoplasm. $\mathbf{f}$ Cross-talk between miRNA biogenesis machinery and the innate immune response. RIG-I and PKR are the cytoplasmic sensors of foreign RNA. Upon foreign dsRNA recognition and activation, PKR blocks translation by the phosphorylation of the eukaryotic translation initiation factor $2 \alpha(\mathrm{eIF} 2 \alpha)$ and induces IFN signaling pathways. TRBP and PACT which form a functional complex with Dicer inhibit and activate PKR, respectively. PACT can also activate RIG-I signaling, leading to IRF3/7 and NF- $\mathrm{KB}$ activation, IFN production and antiviral response. g The key miRNA biogenesis proteins undergo various post-translational modifications and subcellular translocation in response to stress conditions. Stress regulates Ago2 by its p38/MAPK-dependent phosphorylation at serine 387 ; hydroxylation at proline 700 and epidermal growth factor (EGFR)-dependent phosphorylation at tyrosine 393, which reduces the binding of Ago2 to Dicer and inhibits the processing of tumor-suppressor-like miRNAs. Heat and $\mathrm{H}_{2} \mathrm{O}_{2}$ stress induce Drosha phosphorylation by $\mathrm{p} 38 / \mathrm{MAPK}$ leading to its reduced binding to DGCR8 and cytoplasmic translocation. Ago proteins loss their activity as a result of stress-induced poly(ADP-ribosyl)ation

precursors, also known as pre-miRNAs, with a characteristic stem-loop structure, are transported from the nucleus by exportin-5 (EXP-5). Further processing in the cytoplasm is carried out by the second RNase III, Dicer and its cofactors TAR RNA-binding protein (TRBP) and the protein activator of PKR (PACT), resulting in the formation of a miRNA duplex. After duplex unwinding by the helicase activity of Dicer, one miRNA strand (guide strand) is packed into the
RNA-induced silencing complex (RISC), while the other strand (passenger strand) is rapidly degraded. The miRNAcontaining RNA-induced silencing complex (miRISC), with the catalytic component an Argonaute (Ago) protein, recognizes the imperfectly matched complementary sequences in its target, localized mainly in 3' UTRs, leading to the translational repression and/or accelerated transcript degradation by uncapping and deadenylation. The miRNAs recognize their targets primarily through complementarity within the seed sequence - at nucleotides 2-8 of the $5^{\prime}$ miRNA end.

There are many examples of the non-canonical miRNA biogenesis pathway. For example, some miRNAs are grouped in clusters and are transcribed/processed together; intronic pri-miRNAs (mirtrons) are Drosha-independent and are released by the spliceosome [8]; some miRNAs can be processed independently of Dicer with the use of Ago2, which can cleave the miRNA precursors and produce mature miRNAs; and recently discovered agotrons escape the conventional biogenesis pathway entirely and associate with Ago proteins as full-length introns [9].

The number of steps and protein factors involved in miRNA biogenesis offer numerous possibilities to fine-tune this process to precisely regulate the mature miRNA levels. Perturbation of cellular homeostasis may disrupt each of the miRNA biogenesis steps, leading to deregulation of pathways and complex gene expression networks controlled by miRNAs. As a result, the cell is more prone to stress and its harmful effects. Such a deregulation is observed in a variety of human diseases, including cancers as well as metabolic and cardiovascular diseases. miRNAs can function as oncogenes or tumor suppressors, and generally miRNA downregulation is observed in tumor cells [10,11]. It has been demonstrated that altered expression of miRNA in response to stress (radiation) can suppress resistance of cancer cells to therapy [12]. miRNAs are also useful for the classification, diagnosis, prognosis and experimental treatments of diseases [13]. Therapeutic agents and their delivery carriers may also serve as specific types of stressors, which may activate cellular sensors of foreign RNA and DNA or induce DNA damage response (DDR) [14].

Numerous studies have shown that DNA damage stress changes the global profile of miRNA expression [15-17]. The second type of stressors widely studied in the context of miRNA deregulation is pathogen infection and innate immune response activation $[18,19]$. In this review, we will focus on stress-induced changes in miRNA transcription, processing and activity. The published data presented here support the hypothesis that stress directly influences not only the miRNA quantity but also the functioning of the core miRNA biogenesis proteins as well as affects the final length and sequence of mature miRNA (isomiRs). We also discuss the role of chronic stress and miRNA deregulation 
in the context of age-associated neurodegenerative disorders, such as Alzheimer's disease (AD), Parkinson's disease (PD), Huntington's disease (HD) and amyotrophic lateral sclerosis (ALS).

\section{Modulation of transcription upon stress}

Similar to any other gene products, the expression of miRNAs is controlled at the transcriptional level by transcription factors, and in recent years, the knowledge of miRNA promoters and regulators has deepened considerably [20]. Nevertheless, the level of mature miRNA is not simply the result of transcription, but its stability and processing steps also influence the cell-type and stage-specific expression. Even subtle changes in miRNA levels (approximately twofold) may induce significant physiological effects upon stress conditions by regulating transcription factors [21] and other signaling molecules. There are examples of miRNAs working within positive, negative and double-negative feedback loops, which allows for the regulation of the signal strength and the duration of the stress response [1].

An example of transcriptional regulation of miRNA expression upon stress is DNA damage response, an evolutionarily conserved system to maintain genome integrity in eukaryotes [2]. Genotoxic agents, such as UV radiation, ionizing radiation (IR), oxidative stress and chemical mutagens, can activate transcription factors, including p53, NF- $\kappa$ B, c-Myc, and c-Jun, that up- or down-regulate the expression of specific miRNAs.

\section{miRNA regulation by $\mathbf{p 5 3}$}

A decade ago seven groups reported independently that the transcription factor encoded by the p53 tumor suppressor gene is a key regulator of the miR-34 family genes [22-28]. Under basal conditions, p53 expression level is tightly regulated by its ubiquitin-mediated degradation and repression by miR-125b [29]. A wide range of stresses, including DNA double-strand breaks activate ataxia-telangiectasia mutated (ATM) serine/threonine kinases that in turn phosphorylate p53 to arrest cell cycle for DNA repair [1]. Active p53 induces the transcription of $\mathrm{miR}-34 \mathrm{a}$ and $\mathrm{miR}-34 \mathrm{~b} / \mathrm{c}$ genes that repress the expression of target genes (such as the transcription factor c-Myc) to promote the induction of apoptosis, cell cycle arrest, and senescence [30]. A highly conserved p53 binding site is located near the transcription start site of miR34a and $\mathrm{miR} 34 \mathrm{~b} / \mathrm{c}$ genes. It was previously proposed that due to high sequence homology, they regulate the same targets, mainly cell cycle-regulatory genes [22, 25]; however, a recent study suggests that $\mathrm{miR}-34 \mathrm{a}$ and $\mathrm{miR}-34 \mathrm{~b} / \mathrm{c}$ might serve different biological functions [31]. According to the miRTarBase, hsa-miR-34a has 670 targets, and more than 100 of these were validated with the use of two or more methods [32]. Some of these targets include are cyclin dependent kinases (CDK4/6), cyclin E2 (CCNE2), BCL2, MYC, MET and E2F transcription factor 5 (E2F5). The introduction of miR-34a into healthy or tumor cells induces senescence and apoptosis, whereas the inhibition of miR$34 \mathrm{a}$ with the use of antimiR-LNA reduces DNA-damaged induced apoptosis [26].

Morover, p53 can transcriptionally activate other miRNAs with antiproliferative activities (such as, miR-15a/16, miR-23a, miR-29, miR-107, miR-145, miR-192, miR-194, miR-215, miR-605, let-7) and transcriptionally repress miR-17-92 cluster and miR-221/222 [30] (Fig. 1b). For example, miR-15a/16, miR-29, miR-192, miR-215 and let7 target the oncogene BCL2 regulating DNA damageinduced apoptosis [27]. In addition, miR-29 participates in a negative feedback loop by down-regulation of its targets that are negative regulators of p53 (CDC42 and the p85 $\alpha$ regulatory subunit of phosphoinositide-3Kinase PI-3K) [33]. P53/PI-3K/Akt -mediated activation of miR-145 reduces the expression of proto-oncogene c-Myc, resulting in the inhibition of tumor cell growth both in vitro and in vivo [34]. Interestingly, c-Myc-mediated transcriptional effects for many miRNAs are opposite to those regulated by p53. The miR-34 family of genes is repressed by a c-Myc similar to miR-15a/16, miR-23a, and miR-29. However, p53- repressed miRNAs such as miR-17-92 and mi221/222 are activated by c-Myc.

\section{miRNA regulation by $\mathrm{NF}-\kappa \mathrm{B}$}

The transcription factor NF-kappa-B that is expressed in almost all cell types plays a crucial role in cell proliferation, differentiation, immunity, inflammation, and stress response through regulating the expression of a variety of genes. It responds to a broad range of different stimuli, including cytokines, UV and X-ray, free radicals, viruses (proteins, dsRNA) and bacterial lipopolysaccharide (LPS). The aberrant activation of $\mathrm{NF}-\kappa \mathrm{B}$ has been linked to inflammatory and autoimmune disorders as well as cancer. Generally, p53 and NF- $\kappa \mathrm{B}$ have opposing effects in cells (apoptosis and cell cycle arrest for p53 versus survival and proliferation for NF- $\mathrm{BB}$ ), and therefore, cannot function at the same time [35].

A direct link between stress-induced NF- $\mathrm{NB}$ activation and the up-regulation of some miRNAs, including miR21, miR-155, miR-9, and $\mathrm{miR}-146 \mathrm{a} / \mathrm{b}$, has been reported [36] (Fig. 1c). The first example, the oncogenic miR-21, 
is deregulated in a significant number of diseases including solid tumors. Genotoxic agents up-regulate miRNA-21 expression by recruiting NF- $\mathrm{KB}$ and signal transducer and the activator of transcription 3 (STAT3) to the miR-21 promoter region. This cooperative action is mediated by the NF- $\kappa B$-dependent IL-6 up-regulation that is responsible for STAT3 activation upon genotoxic stress [37]. A complex relationship between miR-21 and NF- $\kappa \mathrm{B}$ has been reported [38]. Depending on the cell type, miR-21 may positively or negatively regulate NF- $\mathrm{BB}$; for example, in epithelial cells, miR-21 acts to down-regulate phosphatase and tensin homolog (PTEN), activate protein kinase B (known as AKT), and increase NF- $\mathrm{KB}$ activation promoting survival and growth; in LPS-stimulated macrophages, miR-21 works to inhibit NF- $\mathrm{KB}$ and its proinflammatory signaling $[39,40]$.

Upon inflammatory stimuli (for example, Toll-like receptor ligands and proinflammatory cytokines) in immune cells, NF- $\kappa \mathrm{B}$ up-regulates the transcription of inflammatory-responsive genes as well as miR-9, miR-155 and miR-146a/b, which down-regulate the proinflammatory signaling cascade in a negative feedback loop. For example, NF- $\mathrm{KB}$-mediated miR-146a production is rapidly up-regulated after the exposure of myeloid and $\mathrm{T}$ cells to LPS, tumor necrosis factor alpha (TNF- $\alpha$ ) and interleukin 1 beta (IL-1 $\beta$ ). This results in the silencing of TNF receptor associated factor 6 (TRAF6) and interleukin 1 receptor associated kinase 1 (IRAK1), which are NF- $\mathrm{kB}$ activators. Interestingly, mature miRNAs accumulate later than immediately transcribed pri-miRNAs, and this delay acts as the timer for stress response during inflammation. MiR-146a is also up-regulated during vesicular stomatitis virus (VSV) infection in mouse macrophages. This effect depends on the viral RNA recognition by the cytoplasmic sensor retinoic acid-inducible gene I (RIG-I) and the subsequent NF- $\mathrm{KB}$ activation. Through targeting TRAF6, IRAK1 and IRAK2, miR-146a negatively regulates VSV-triggered type I IFN production and antiviral response [41].

The final regulatory effect of miRNA is a result of the relative concentration of miRNA and its targets; therefore, the stress-induced up- or down-regulation of one component influences the other. This interplay results in a specific timing of target gene expression. The important feature of these networks is that individual miRNA regulates multiple targets, and transcription factors become key activators of these pathways by regulating both miRNAs and their targets. Moreover, one mRNA target may be under the control of multiple miRNAs that may bind cooperatively $[42,43]$. Such a complex regulatory system allows for a rapid stress response, signal strength regulation and restoration of cellular homeostasis.

\section{miRNA biogenesis and stress}

The direct comparison of pri-miRNA, pre-miRNA and mature miRNA forms revealed that in some cases, their amounts were not correlated. Growing evidence indicates that stress regulates not only transcription but also the biogenesis of miRNAs [18, 30, 44-46]. Different stressors may induce the accumulation of pre-miRNAs and the reduction of mature miRNAs, or they can facilitate the processing of some miRNAs. In addition to expanding our knowledge on miRNA biogenesis, numerous factors working within miRNA biogenesis complexes and the co-regulators of miRNA precursor maturation were identified (Fig. 1d-g). The vast majority of examples describing various regulatory effects applies to the microprocessor step of miRNA biogenesis and transcription factors, including SMADs, p53 and breast cancer 1 (BRCA1), which are key players in this process (Fig. 1d).

The first transcription factors that were found to regulate miRNA biogenesis are SMAD proteins [47]. The Hata group demonstrated that SMADs transduce signals from the transforming growth factor- $\beta$ (TGF- $\beta$ ) and the bone morphogenetic protein 4 (BMP4) and mediate the rapid, posttranscriptional induction of miR-21 and miR-199a in human primary pulmonary smooth muscle cells. Upon stimulation, the Receptor-specific SMADs (R-SMADs) undergo phosphorylation, translocate to the nucleus, associate with the Drosha/DGCR8/p68 microprocessor complex, and facilitate the cleavage of pri-miRNA to pre-miRNA by Drosha. SMADs recognize specific sequence motifs within the primiRNA stem region (5'-CAGAC-3'), and the mutation of this sequence abrogates the ligand-induced recruitment of the microprocessor complex and processing [48]. There are approximately 20 miRNAs that are regulated post-transcriptionally by ligand-dependent induction of TGF- $\beta / \mathrm{BMP}$ and SMAD proteins.

In addition to its role in transcriptional gene regulation, p53 was shown to post-transcriptionally regulate the expression of various miRNAs, including miR-16-1, miR-143, miR-145 and miR-206 [30]. It has been demonstrated that after the stimulation of the human colon cancer cell line (HCT116) with DNA-damaging agent doxorubicin, some miRNAs show increased expression of their pre- and mature forms in contrast to primary transcripts, which remained unchanged. This effect was p53- and p68/p72-dependent. As a result of DDR, p53 interacts with the microprocessor complex through direct binding to p68 and enhances the Droshamediated processing of several miRNAs (Fig. 1d). Through targeting cell cycle and proliferation pathways, miRNAs support the growth-suppressive function of p53 upon stress conditions. This regulatory network is further complicated by the fact that tumor suppressor BRCA1 can facilitate the 
processing of pri-let-7a-1, pri-miR-16-1, pri-miR-145, and pri-miR-34a by direct RNA binding and association with the Drosha microprocessor complex and SMADs/p53 [49]. BRCA1 is activated by ATM after DNA damage and plays a crucial role in DNA repair.

The step of pri-miRNA to pre-miRNA processing is also controlled by single-stranded RNA- binding KH-type splicing regulatory protein (KSRP), a key component of both Drosha and Dicer miRNA-processing complexes [50]. Trabucchi et al. demonstrated that KSRP selectively binds to the terminal loop of some pri-miRNAs, with preference to short G-rich stretches, and facilitates their processing [50]. KSRP knock-down in both HeLa and NIH-3T3 cells revealed that the levels of mature let-7a, mir-16, miR-20a, miR-21, miR-26b and miR-106a were reduced by $40-70 \%$. Further studies identified a direct interaction between KSRP and ATM kinase [51]. Upon DNA damage, the ATM kinase directly phosphorylates KSRP and facilitates its function in miRNA maturation. A similar regulatory pathway is demonstrated for the double-stranded RNA-binding protein DDX1, which also promotes the maturation of a subset of miRNAs (such as the miR-200 family), and the majority of them are induced by DNA damage [52]. Phosphorylation of DDX1 by stressinduced ATM kinase enhances its binding to pri-miRNAs and recruiting the Drosha complex [52].

During C2C12 myoblast differentiation PI3 K/AKT kinase signaling activation induces the expression of myomiRs (e.g., miR-206) by KSRP-dependent facilitation of pri-miRNA to pre-miRNA processing [53]. Phosphorylation of KSRP by AKT inhibits its ability to bind with mRNA and promotes the pri-miRNA-binding. A similar effect was also observed in the immune system [54]. LPS is a glycolipid of the outer cell membrane of Gramnegative bacteria. It is recognized by the transmembrane protein toll like receptor 4 (TLR4) that activates various transcription factors, including NF- $\mathrm{\kappa B}$, leading to the increased production of proinflammatory cytokines, such as TNF- $\alpha$ and IL-6. In macrophages, LPS significantly induces the expression of miR-155, and this induction depends on KSRP-mediated enhanced maturation of its precursor [54].

Another example of a protein involved in miRNA biogenesis is hnRNP A1, which by binding to the loop of pri-miR-18a promotes its cleavage by Drosha [55]. Interestingly, it has an antagonistic effect to KSRP during the let-7a biogenesis [56].

It has been shown that key miRNA biogenesis proteins, such as Drosha, Dicer and Ago2, are down-regulated by hypoxia [57-59]. Upon oxidative stress, a total pool of pre-miRNA and miRNA in myoblasts is decreased through DGCR8 regulation by heme oxygenase-1 (HMOX1) [60] (Fig. 1d). Heme is essential for
DGCR8 activity [61], and the heme-binding domain of DGCR8 plays a key role in pri-miRNA recognition [62]. Hypoxic stress also regulates Ago2 by its phosphorylation (EGFR-dependent and p38/MAPK-dependent) [63, 64] and hydroxylation [65], which reduces the binding of Ago2 to Dicer or directs Ago2 to stress granules [66], respectively. Ago function is also regulated by stressinduced poly(ADP-ribosylation) [67, 68] (Fig. 1g).

\section{Interferon regulation of miRNA biogenesis and functioning}

In mammals, the innate immune response plays a key role in response to stress induced by pathogen-associated molecular patterns (PAMPs). The signals derived from microorganisms include unmethylated CpG DNA, double-stranded RNA, 5'-triphosphate RNA and LPS. PAMPs are recognized by cells via conserved sensors, known as pattern-recognition receptors (PRRs), such as Toll-like receptors, an IFN-inducible dsRNA-activated protein kinase (PKR) and retinoic acid-inducible gene I (RIG-I)—-like receptors (RLRs). After stimulation, PRRs induce intracellular signaling pathways, involving transcription factors [e.g., NF-B, activator protein 1 (AP-1), IFN regulatory factors (IRFs)], and the synthesis of signaling molecules, such as cytokines, chemokines, and immunoreceptors. IFN production subsequently results in the up-regulation of approximately 2000 IFN-stimulated genes (ISGs) in an IFN subtype-, dose-, cell-type- and stimulus-dependent manner [69]. There are more than 30 known miRNAs regulated by type I IFNs, including those regulated by IFN $\beta$ (miR-155, miR-129 and miR-196a), IFN $\alpha$ (for example, miR-143 and miR-378), and both IFN $\beta$ and IFN $\alpha$ in a cell type-specific manner (such as the let-7 family and miR-30) [19]. IFNs up-regulate miRNAs with antiviral activity (such as miR-29 and miR-196b). For example, the expression of miR-196b and eight other miRNAs predicted to target HCV RNA is modulated upon type-I IFN treatment of primary mouse hepatocytes, Huh7 cells [70] and human peripheral blood mononuclear cells (PBMC) [36]. Contrarily, the antiviral effects were also observed by the down-regulation of liver-specific miR-122 in response to $\operatorname{IFN} \beta[70,71]$.

Moreover, many core miRNA biogenesis proteins have also been implicated in the IFN response. Down-regulation of Ago1 and Ago2 [19, 69] was observed in lung and blood cells $24 \mathrm{~h}$ post-IFN $\alpha$ stimulation. Dicer down-regulation was observed $72 \mathrm{~h}$ after IFN $\alpha$ and poly(I:C) treatment in JAR and HeLa cells as well as in mice and human tissues [72]. This effect was not correlated with apoptosis. Furthermore, oxidative stress selectively inhibits Dicer but not Agol in JAR cells. Contrastingly, IFN- $\gamma$ (type II class of IFNs) upregulates Dicer in JAR and HeLa cells [72]. 
A well-known example of the link between miRNA biogenesis machinery and the innate immune response is TRBP/PACT and PKR cross-talk [73-77] (Fig. 1f). Knocking down TRBP and PACT influences miRNA biogenesis; however, there are some differences between studies performed in vitro and in cells [78-80]. TRBP controls mature miRNA length and strand selection [81]. The depletion of TRBP in vitro and in mouse and fly systems results in the lower accuracy of Dicer cleavage, leading to the generation of shorter iso-miRs [82, 83]. TRBP and PACT, both of which form a functional complex with Dicer [74, 83], have been reported to inhibit and activate PKR, respectively. Upon foreign dsRNA recognition and activation, PKR blocks translation by the phosphorylation of a eukaryotic translation initiation factor $2 \alpha(\mathrm{eIF} 2 \alpha)$ and induces IFN signaling pathways. A transient blockade in translation directs cellular metabolism toward damage repair. TRBP is hyperphosphorylated by c-Jun N-terminal kinase (JNK) when PKR is activated by dsRNA, and this modification enhances the inhibitory activity of TRBP on PKR [84]. It has been demonstrated that during viral infection PACT directly binds to the other cytoplasmic sensor of foreign RNA, RIG-I and stimulates its ATPase activity to trigger innate antiviral response [85].

miRNA biogenesis and regulatory networks may be disturbed by stressors in the form of exogenous RNA and DNA (such as plasmid DNA, antisense oligonucleotides, RNA interference tools, antimiRs or miRNA sponges) used in various experimental approaches, including therapy $[14,86,87]$. It has been recently reported that a genetic tool Cre/loxP-based recombination system may induce DNA damage and accumulation of cytoplasmic DNA products that are sensed by the cytoplasmic sensor of DNA-STING [88]. Thus, strong type-I IFN antiviral response in different mouse and human cell models was observed. Since a wide range of genes may be stimulated by IFNs, we speculate that it may influence miRNA biogenesis and functional networks; however this hypothesis remains to be corroborated. A deeper insight into similar problems is also required in the context of genome editing technology.

\section{Changes in miRNA/protein complex localization upon stress}

The export of pre-miRNA from the nucleus is another key step of miRNA biogenesis that undergoes regulation and may determine the level of active miRNA in the cytoplasm. Pre-miRNAs are transported by EXP-5 (encoded by XPO5), a Ran guanosine triphosphate (RanGTP)-dependent dsRNA-binding receptor [89]. There are only a few reports describing the role of stress in the regulation of pre-miRNA transport. More than a decade ago, the Kay group reported that the overexpression of artificial pre-miRNAs (short hairpin RNAs) in the liver of adult mice saturates the miRNA biogenesis pathway at the EXP-5 step [90]. This leads to the high toxicity of reagents in vivo and the down-regulation of liver-derived miR-122 (Fig. 1e).

The opposite effect was observed upon DNA damage, when ATM-activated AKT kinase phosphorylates Nup153, an important nucleopore component, thus enhancing its interaction with EXP-5 and promoting the export of premiRNAs into the cytoplasm [91] (Fig. 1e). Another export protein that facilitates the transport of RNAs and proteins across the nuclear membrane to the cytoplasm is Exportin-1 (EXP1, also known as the Chromosomal Maintenance 1). Some non-canonical pre-miRNAs (e.g., pre-miR-320) are transported by EXP1 [92]. Interestingly, a broad range of viral PAMPs, including dsRNA, trigger EXP1-mediated Drosha translocation from the nucleus to the cytoplasm in murine fibroblasts [93]. Heat and $\mathrm{H}_{2} \mathrm{O}_{2}$ stress might induce Drosha phosphorylation by $\mathrm{p} 38$ MAPK, leading to its cytoplasmic translocation, which was responsible for the reduced binding of DGCR8 by Drosha and its destabilization and degradation by calpain [94] (Fig. 1g).

Under stress, cell metabolism is diverted toward survival and eventual recovery. One way to conserve energy is to limit the translation and focus only on producing proteins needed for survival. In eukaryotic cells, non-translating mRNAs and their associated RNA-binding proteins aggregate into structures called ribonucleoprotein (RNP) granules. They form within minutes in response to stress to protect cellular mRNAs. Subcellular structures known as processing bodies (PBs) are the major sites of RNA processing and degradation in most cells [95]. During the stress-induced translational arrest, stalled initiation complexes and mRNAs with RNA-binding proteins assemble into stress granules (SG) [44, 96, 97]. miRNAs and proteins involved in miRNA biogenesis have also been shown to associate with SG following the onset of cell stress. For example, arsenite treatment triggers Ago2 relocalization into stress granules [98]. Moreover, oxidative stressors enhance the interactions of many proteins, including Ago2 and SG components, with Dicer, resulting in its inhibited catalytic activity [45]. UV irradiation and $\mathrm{H}_{2} \mathrm{O}_{2}$ also induced $\mathrm{SG}$ formation but only in a cell cycle-dependent mode [16]. The accumulation of cytoplasmic granules is a known hallmark of neurodegenerative disorders and will be described in the last section.

\section{miRNA modifications in response to stress}

Stress-induced post-transcriptional modifications of miRNAs include changes in the miRNA sequence, modifications of miRNA ends and "strand switching." 
Inflammation-induced adenosine deaminase acting on RNA (ADAR) up-regulation can influence pri-miRNA processing [99]. Conversion of adenosine to inosine (recognized as guanosine) is the most prevalent form of RNA modification in higher eukaryotes. Modified transcripts are recognized by the cellular sensor of dsRNA (MDA5) as self versus non-self viral RNAs [100]. The A-to-I editing can alter the structure of pri-miRNAs, which may result in (1) miRNA processing inhibition [99, 101, 102] or (2) activation [103], (3) new mRNA targets recognition and (4) RISC loading suppression. For example, the small RNA-seq data from a hypoxiatreated breast cancer cell line identified 31 statistically significant modification sites in 21 different miRNAs. Most A-to-G modifications occurred in seed regions, whereas the levels of miRNA modifications generally increased with the time of exposure to stress. These modifications may have a direct influence on targeting, as shown for miR-27a-3p [104]. Expression profiling of small RNAs from brain tissues showed that more than $80 \%$ of miRNA is heterogeneous in length, and 3'-trimming variants were the most predominant [46]. Among isomiRs in the seed region, $\mathrm{A}-\mathrm{G}$ changes were frequent at position 5 (miR-411 and miR-379), position 6 (miR-376 cluster) and several other positions (miR320) [46]. Regardless of the catalytic activity, ADAR1 can also form a functional complex with Dicer and Ago2. This protein-protein interaction is responsible for the induction of conformational changes and increasing the rate of premiRNA processing by Dicer, RISC assembly, and loading of miRNA [105].

Pre-miRNAs and miRNAs are often heterogeneous at their $3^{\prime}$ and $5^{\prime}$ ends as a result of imprecise Drosha and/ or Dicer cleavage and tailing (non-templated nucleotidyl addition to the $3^{\prime}$ end of RNA) or trimming activity [46, 106]. Despite the fact that most miRNAs are $3^{\prime}$ tailed or $3^{\prime}$ trimmed, the biological significance of isomiRs in most cases remains unknown. The $5^{\prime}$ end variants with changed seed sequence may regulate different sets of target genes. However, the 3' end modifications (adenylation and deadenylation) have been associated with specific functional consequences [107, 108]. After transport into the cytoplasm, some pre-miRNAs are modified by uridylation, which is one of the most frequent types of RNA tailing [109]. RNA tailing is carried out by terminal uridylyl transferases (TUTases) that recognize the overhang of a pre-miRNA. For example, TUT4 recruited by Lin-28, mediates the uridylation of prelet-7 miRNA [110], thus preventing the further processing of pre-let-7 miRNA and inhibiting its function.

Recently, we demonstrated that plasmid-based RNA interference reagents, empty vectors and poly(I:C) induce changes in the composition of $3^{\prime}$ miR-221/222 isomiRs in human fibroblasts [87]. As the transfection of all these reagent types induces apoptosis, miR-221/222 shortening may be part of this process. The mechanism of these $3^{\prime}$
isomiRs formation and the role of shorter miRNA variants is unknown; however, it may result from altered pri-miRNA processing by Drosha or stress-induced miRNA trimming. The length of the 3 '-terminus of a miRNA may modulate its interaction with the target, and therefore, it may influence miRNA stability [111]. We speculate that stress conditions may also change the relative ratio of canonical vs. non-canonical targets of miR-221/222, thus stabilizing some isomiR variants.

Microbial infections influence miRNA repertoire [112]. For example, the miR-15 family is down-regulated during Salmonella infection through the inhibition of the transcription factor E2F1 [113]. Virulent mycobacteria induce the expression of the miR-132/212 family [18]. Infection can alter the relative expression of the miRNA arms (arm switching), as it was shown for miR-361 and miR-582 following Yersinia pseudotuberculosis infection [18]. Bacterial infection can also change the isomiR distribution in infected cells with the most predominant form of $3^{\prime}$ isomiRs. Interestingly, seven miRNAs showed a change in the $5^{\prime}$ end, thus altering a seed sequence [18].

As we described earlier, miR-34 is regulated in cells by p53 during DNA damage response. Salzman et al. demonstrated that there is a pool of inactive mature miR-34 in cancer cell lines [114]. Radiation-induced ATM/hClp1 kinase activates this pool by phosphorylation of miR-34 at the $5^{\prime}$ end. This mechanism, independent of the de novo transcription and processing, represents the rapid response of the cell to environmental stimuli.

\section{Chronic stress-miRNA in neurodegeneration}

Over the past decade, miRNAs have emerged as important regulators of aging and neurodegeneration. Neurodegenerative diseases are a group of late-onset progressive disorders resulting from the increased accumulation of toxic proteins and leading to neuronal dysfunction. The disease progression may be further modulated by aging and environmental factors such as infections or exposure to toxins. Moreover, the role of inflammation in neurodegeneration is well documented $[115,116]$. Because harmful molecules accumulate over time in non-dividing neurons, they may act as chronic stressors. The best-studied neurodegenerative diseases are PD, AD, HD and ALS. The role of individual miRNAs in the pathogenesis of these diseases and their potential as biomarkers and therapy targets has been intensively studied [117-122]. Many deregulated miRNAs have been reported in cell lines, patients' tissues and animal models of neurodegenerative disorders (Supplementary Table 1). However, it is not clear if this is a cause or a consequence of the disease. Some deregulated miRNAs are common for different disease models (such as miR-9, miR-29, miR-34a/b/c, miR-125, 
miR-128, miR-132 and miR-424) [118, 122-138], whereas others are disease-specific [139-147]. Here, we characterize toxic proteins specific for selected diseases and present a few examples of miRNA deregulation in neurodegenerative disorders.

The classic pathological feature of PD is the loss of midbrain dopaminergic neurons (DNs) of the substantia nigra and the presence of cytoplasmic inclusions (called the Lewy bodies) in the remaining neurons [148]. The maturation and functioning of the DNs are regulated by miR-133b that works within a negative feedback loop with pairedlike homeodomain transcription factor Pitx $3[149,150]$. Expression analysis confirmed by RNase protection assays and northern blotting revealed that miR-133b (both pre- and mature miRNA) was specifically absent in PD patient samples and the midbrain of Pitx3 mutant Aphakia mice [149]. The transcription factor Pitx 3 is a direct target of miR-133b, and the overexpression of Pitx3 leads to the up-regulation of pre-miR-133b. Other miRNAs deregulated in PD include miR-7, miR-10b, miR-34b/c, miR-132, miR-135a and miR433 [132, 138-140, 151-153].

Common neuropathological features of $\mathrm{AD}$ cases are $\beta$-amyloid neuritic plaques accumulation and intraneuronal neurofibrillary tangles (containing tau protein). Beta secretase 1 protein (BACE1) is responsible for the cleavage of amyloid precursor protein (APP) and amyloid $\beta$ production. Alpha-synuclein ( $\alpha$-syn) insoluble fibrils are found in both sporadic and familial cases with $\mathrm{AD}$ and rare Mendelian forms of PD. APP and BACE1 are targeted by numerous miRNAs, including miR-9, miR-16, miR-106b, miR-107, miR-124, miR-153, miR-195 and miR-29, which are down-regulated in AD patients (Supplementary Table 1) [119, 154-161]. In some cases, the miRNA deregulation was AD grade-dependent. For example, miR-16 and miR146a were up-regulated in early AD cases (Braak III/IV) and down-regulated in hippocampal samples from the late stages of AD (Braak VI). Lower levels of miR-146a were also observed in the cerebrospinal fluid (CSF) of AD cases [119].

Elevated levels of miR-34c were observed in the circulating blood plasma [162], the hippocampus of AD patients and the corresponding mouse models [133]. miR-34c inhibitors reinstated learning behavior and physiological SIRT1 levels (miR-34c target), indicating that miR-34c directly contributes to $\mathrm{AD}$ and age-associated memory impairment. Contrastingly, the expression profiling of PD brain samples revealed that $\mathrm{miR}-34 \mathrm{~b} / \mathrm{c}$ are down-regulated at early (premotor) and late (motor) stages of the disease. The authors suggested that the depletion of miR-34b/c leads to mitochondrial dysfunction, oxidative stress, and a decrease in the expression of DJ1 and Parkin associated with familial forms of PD [132]. Further inhibition of miR-34b/c in SH-SY5Y cells increased $\alpha$-syn levels and stimulated aggregate formation, thus confirming the role of the miR-34 family in neurodegeneration [163].

HD is the best-known example of a group of dominantly inherited neurological diseases caused by the expansion of unstable CAG repeats in coding regions of the associated genes. This group also includes spinocerebellar ataxia type 1, 2, 3, 6, 7 and 17 (SCA), spinobulbar muscular atrophy (SBMA) and dentatorubral-pallidoluysian atrophy (DRPLA). Toxic polyglutamine (polyQ)-rich proteins form intracellular aggregates that affect numerous cellular activities leading to neurodegeneration. Moreover, mutant transcripts may also play an important role in neurodegeneration, as it was shown for untranslated trinucleotide diseases such as myotonic dystrophy type 1 (DM1). The common feature of various cell lines modeling polyQ diseases is the formation of nuclear RNA foci containing transcripts with an expanded CAG tract. Strong miRNA and isomiR expression deregulation were observed in the frontal cortex and the striatum of HD patients [46]. In the group of deregulated miRNAs, p53 and RE1 silencing transcription factor (REST) targets were enriched, suggesting the role of these transcription factors in HD pathogenesis. Gaughwin et al. demonstrated by qPCR assay that p53-regulated miR-34b is up-regulated in response to mHTT in both pluripotent and neuronally differentiated human cells and in human plasma. Interestingly, significantly elevated levels of miR-34b were observed in plasma from the HD gene carriers before symptom onset and therefore may be used as a biomarker for HD [118]. Massive parallel sequencing of small RNA libraries revealed that miR-34c is highly enriched in the hippocampus, in contrast to the miR-34b, which is transcribed from the same cluster [133].

MiR-9 and miR-124a regulate neuronal proliferation and differentiation. As a key regulator of microglia quiescence in the CNS, miR-124a helps in preventing CNS inflammation [164]. Such abundant miRNAs in the brain are regulated by the REST-inhibitor of neuronal gene expression in a nonneuronal cell. Mir-9/9* is decreased early in HD and targets REST and corepressor for REST (CoREST), respectively, forming double negative feedback loop [123]. Interestingly, unchanged pre-miR-124a [126] levels in contrast to reduced mature miRNA levels were observed in the HD cortex [123], implying post-transcriptional regulation. Decreased levels of miR-124 were also found in AD brains, suggesting the role of miR-124 in pathology of AD and HD.

ALS is caused by the mutations in protein-coding genes such as TDP-43, FUS and hnRNPA1. These RNA-binding proteins contain prion-like domains that allow them to rapidly self-associate and form RNP granules in the cytoplasm of motor neurons. At physiological conditions, TDP-43 and FUS are nuclear proteins that can be reversibly shuttled 
to the cytoplasm upon stress, where they associate with SGs. This shuttling is dysregulated in ALS; however, it is unclear if this mislocalization and SG aggregation is a cause or consequence of the disease $[165,166]$. Interestingly, TDP-43 is a component of the Drosha and Dicer complexes and promotes microRNA biogenesis in the nucleus and cytoplasm [167]. It has been demonstrated that the disruption of the miRNA biogenesis pathway by Dicer silencing causes degeneration of various neural cell types in culture and in vivo [168]. Decreased Dicer catalytic activity resulting in global miRNA down-regulation was observed in the motor neurons of ALS patients [45]. The authors suggest that stress and SG formation are responsible for the dynamic changes in Dicer interactions with protein factors, including Ago2 leading to deregulation of miRNA processing.

\section{Conclusion}

Organisms are constantly exposed to various stresses throughout their lives. Some of them induce temporal changes in cellular homeostasis, whereas others deregulate the system permanently, leading to cancers, neurodegeneration or pathogen infections. miRNAs are wellknown guardians of cellular homeostasis and, together with transcription factors and protein partners, regulate stress responses. In this review, we have presented only the basic information regarding the vast number and variety of potential stressors, miRNAs, and their regulatory networks. Expression profiling methods will help in identifying upand down-regulated miRNAs upon stress; however, less is known about the mechanisms underlying these effects. Our knowledge about the post-transcriptional regulation of miRNA biogenesis and functioning under stress conditions is still in its infancy. The role of isomiR variants and the interaction of miRNAs with non-canonical targets is an important and currently unrecognized topic in the context of stress and apoptosis. Finally, a better understanding of pathways and mechanisms leading to miRNA dysregulation in aging and neurodegeneration will assist in the determination of new biomarkers for disease and potential therapeutic targets.

Acknowledgements This work was supported by a grant from the National Science Center (N N302 633240 and 2015/18/E/NZ2/00678), and from the quality-promoting subsidy under the Leading National Research Center (KNOW) program for the years 2014-2019.

\section{Compliance with ethical standards}

Conflict of interest The authors declare that there is no conflict of interests regarding the publication of this article.
Open Access This article is distributed under the terms of the Creative Commons Attribution 4.0 International License (http://creativecommons.org/licenses/by/4.0/), which permits unrestricted use, distribution, and reproduction in any medium, provided you give appropriate credit to the original author(s) and the source, provide a link to the Creative Commons license, and indicate if changes were made.

\section{References}

1. Leung AKL, Sharp PA (2010) MicroRNA functions in stress responses. Mol Cell. doi:10.1016/j.molcel.2010.09.027

2. Zhang C, Peng G (2015) Non-coding RNAs: an emerging player in DNA damage response. Mutat Res Rev Mutat Res 763:202211. doi:10.1016/j.mrrev.2014.11.003

3. Leong HS, Dawson K, Wirth C et al (2014) A global non-coding RNA system modulates fission yeast protein levels in response to stress. Nat Commun 5:3947. doi:10.1038/ncomms4947

4. Mendell JT, Olson EN (2012) MicroRNAs in stress signaling and human disease. Cell. doi:10.1016/j.cell.2012.02.005

5. Friedman RC, Farh KKH, Burge CB, Bartel DP (2009) Most mammalian mRNAs are conserved targets of microRNAs. Genome Res 19:92-105. doi:10.1101/gr.082701.108

6. Krol J, Loedige I, Filipowicz W (2010) The widespread regulation of microRNA biogenesis, function and decay. Nat Rev Genet 11:597-610. doi:10.1038/nrg2843

7. Ha M, Kim VN (2014) Regulation of microRNA biogenesis. Nat Rev Mol Cell Biol 15:509-524. doi:10.1038/nrm3838

8. Ruby JG, Jan CH, Bartel DP (2007) Intronic microRNA precursors that bypass Drosha processing. Nature 448:83-86. doi:10.1038/nature05983

9. Hansen TB, Veno MT, Jensen TI et al (2016) Argonaute-associated short introns are a novel class of gene regulators. Nat Commun 7:1-10. doi:10.1038/ncomms11538

10. Kumar MS, Lu J, Mercer KL et al (2007) Impaired microRNA processing enhances cellular transformation and tumorigenesis. Nat Genet 39:673-677. doi:10.1038/ng2003

11. Wu D, Hu Y, Tong S et al (2013) The use of miRNA microarrays for the analysis of cancer samples with global miRNA decrease. RNA 19:876-888. doi:10.1261/rna.035055.112

12. Weidhaas JB, Babar I, Nallur SM et al (2007) MicroRNAs as potential agents to alter resistance to cytotoxic anticancer therapy. Cancer Res 67:11111-11116. doi:10.1158/0008-5472. CAN-07-2858

13. Calin GA, Croce CM (2006) MicroRNA signatures in human cancers. Nat Rev Cancer 6:857-866. doi:10.1038/nrc1997

14. Olejniczak M, Galka-Marciniak P, Polak K et al (2012) RNAimmuno: a database of the nonspecific immunological effects of RNA interference and microRNA reagents. RNA 18:930-935. doi:10.1261/rna.025627.110

15. Wan G, Mathur R, Hu X et al (2011) MiRNA response to DNA damage. Trends Biochem Sci. doi:10.1016/j.tibs.2011.06.002

16. Pothof J, Verkaik NS, van IJcken W et al (2009) MicroRNAmediated gene silencing modulates the UV-induced DNAdamage response. EMBO J 28:2090-2099. doi:10.1038/ emboj.2009.156

17. Han Z, Zhang Y, Xu Y et al (2014) Cell cycle changes mediated by the $\mathrm{p} 53 / \mathrm{miR}-34 \mathrm{c}$ axis are involved in the malignant transformation of human bronchial epithelial cells by benzo[a]pyrene. Toxicol Lett 225:275-284. doi:10.1016/j.toxlet.2013.12.008

18. Siddle KJ, Tailleux L, Deschamps M et al (2015) Bacterial infection drives the expression dynamics of microRNAs and their isomiRs. PLoS Genet. doi:10.1371/journal.pgen.1005064 
19. Forster SC, Tate MD, Hertzog PJ (2015) MicroRNA as type I interferon-regulated transcripts and modulators of the innate immune response. Front Immunol 6:1-9. doi:10.3389/ fimmu.2015.00334

20. Wang Z, Yao H, Lin S et al (2013) Transcriptional and epigenetic regulation of human microRNAs. Cancer Lett 331:1-10. doi:10.1016/j.canlet.2012.12.006

21. Gosline SJC, Gurtan AM, JnBaptiste CK et al (2016) Elucidating MicroRNA regulatory networks using transcriptional, posttranscriptional, and histone modification measurements. Cell Rep 14:310-319. doi:10.1016/j.celrep.2015.12.031

22. Bommer GT, Gerin I, Feng Y et al (2007) p53-Mediated activation of miRNA34 candidate tumor-suppressor genes. Curr Biol 17:1298-1307. doi:10.1016/j.cub.2007.06.068

23. Chang T-C, Wentzel EA, Kent OA et al (2007) Transactivation of miR-34a by p53 broadly influences gene expression and promotes apoptosis. Mol Cell 26:745-752. doi:10.1016/j. molcel.2007.05.010

24. Corney DC, Flesken-Nikitin A, Godwin AK et al (2007) MicroRNA-34b and MicroRNA-34c are targets of p53 and cooperate in control of cell proliferation and adhesion-independent growth. Cancer Res 67:8433-8438. doi:10.1158/0008-5472. CAN-07-1585

25. He L, He X, Lim LP et al (2007) A microRNA component of the p53 tumour suppressor network. Nature 447:1130-1134. doi:10.1038/nature05939

26. Raver-Shapira N, Marciano E, Meiri E et al (2007) Transcriptional activation of miR-34a contributes to p53-mediated apoptosis. Mol Cell 26:731-743. doi:10.1016/j.molcel.2007.05.017

27. Tarasov V, Jung P, Verdoodt B et al (2007) Differential regulation of microRNAs by $\mathrm{p} 53$ revealed by massively parallel sequencing: miR-34a is a p53 target that induces apoptosis and G 1-arrest. Cell Cycle 6:1586-1593. doi:10.4161/cc.6.13.4436

28. Tazawa H, Tsuchiya N, Izumiya M, Nakagama H (2007) Tumorsuppressive miR-34a induces senescence-like growth arrest through modulation of the E2F pathway in human colon cancer cells. Proc Natl Acad Sci USA 104:15472-15477. doi:10.1073/ pnas.0707351104

29. Le MTN, Teh C, Shyh-Chang N et al (2009) MicroRNA-125b is a novel negative regulator of p53. Genes Dev 23:862-876. doi:10.1101/gad.1767609

30. Suzuki HI, Yamagata K, Sugimoto K et al (2009) Modulation of microRNA processing by p53. Nature 460:529-533. doi:10.1038/nature08199

31. Navarro F, Lieberman J (2015) miR-34 and p53: new insights into a complex functional relationship. PLoS One. doi:10.1371/ journal.pone. 0132767

32. Chou CH, Chang NW, Shrestha S et al (2016) miRTarBase 2016: updates to the experimentally validated miRNA-target interactions database. Nucleic Acids Res 44:D239-D247. doi:10.1093/ nar/gkv1258

33. Park SY, Lee JH, Ha M et al (2009) miR-29 miRNAs activate p53 by targeting p85 alpha and CDC42. Nat Struct Mol Biol 16:23-29. doi:10.1038/nsmb.1533

34. Sachdeva M, Zhu S, Wu F et al (2009) p53 represses c-Myc through induction of the tumor suppressor miR-145. Proc Natl Acad Sci USA 106:3207-3212. doi:10.1073/ pnas.0808042106

35. Ak P, Levine AJ (2010) p53 and NF- $\mathrm{kB}$ : different strategies for responding to stress lead to a functional antagonism. FASEB $\mathrm{J}$ 24:3643-3652. doi:10.1096/fj.10-160549

36. Scagnolari C, Zingariello P, Vecchiet J et al (2010) Differential expression of interferon-induced microRNAs in patients with chronic hepatitis $\mathrm{C}$ virus infection treated with pegylated interferon alpha. Virol J 7:311. doi:10.1186/1743-422X-7-311
37. Niu J, Shi Y, Tan G et al (2012) DNA damage induces NF-kBdependent MicroRNA-21 up-regulation and promotes breast cancer cell invasion. J Biol Chem 287:21783-21795. doi:10.1074/ jbc.M112.355495

38. Yang CH, Yue J, Fan M, Pfeffer LM (2010) Interferon induces miR-21 through a STAT3-dependent pathway as a suppressive negative feedback on interferon-induced apoptosis. Cancer Res 70(20):8108-8116. doi:10.1158/0008-5472.CAN-10-2579

39. Iliopoulos D, Jaeger SA, Hirsch HA et al (2010) STAT3 activation of miR-21 and miR-181b-1, via PTEN and CYLD, are part of the epigenetic switch linking inflammation to cancer. Mol Cell 39:493-506. doi:10.1016/j.molcel.2010.07.023

40. Ma X, Becker Buscaglia LE, Barker JR, Li Y (2011) MicroRNAs in NF-kappaB signaling. J Mol Cell Biol 3:159-166. doi:10.1093/jmcb/mjr007

41. Hou J, Wang P, Lin L et al (2009) MicroRNA-146a feedback inhibits RIG-I-dependent Type I IFN production in macrophages by targeting TRAF6, IRAK1, and IRAK2. J Immunol 183:2150 2158. doi:10.4049/jimmunol.0900707

42. Krek A, Grün D, Poy MN et al (2005) Combinatorial microRNA target predictions. Nat Genet 37:495-500. doi:10.1038/ng1536

43. Koscianska E, Witkos TM, Kozlowska E et al (2015) Cooperation meets competition in microRNA-mediated DMPK transcript regulation. Nucleic Acids Res 43:9500-9518. doi:10.1093/nar/ gkv849

44. Emde A, Hornstein E (2014) miRNAs at the interface of cellular stress and disease. EMBO J 33:1428-1437. doi:10.15252/embj

45. Emde A, Eitan C, Liou L-L et al (2015) Dysregulated miRNA biogenesis downstream of cellular stress and ALS-causing mutations: a new mechanism for ALS. EMBO J 34:2633-2651. doi:10.15252/embj.201490493

46. Martí E, Pantano L, Bañez-Coronel M et al (2010) A myriad of miRNA variants in control and Huntington's disease brain regions detected by massively parallel sequencing. Nucleic Acids Res 38:7219-7235. doi:10.1093/nar/gkq575

47. Davis BN, Hilyard AC, Lagna G, Hata A (2008) SMAD proteins control DROSHA-mediated microRNA maturation. Nature 454:56-61. doi:10.1038/nature07086

48. Davis BN, Hilyard AC, Nguyen PH et al (2010) Smad proteins bind a conserved RNA sequence to promote microRNA maturation by Drosha. Mol Cell. doi:10.1016/j.molcel.2010.07.011

49. Kawai S, Amano A (2012) BRCA1 regulates microRNA biogenesis via the DROSHA microprocessor complex. J Cell Biol. doi:10.1083/jcb.201110008

50. Trabucchi M, Briata P, Garcia-Mayoral M et al (2009) The RNAbinding protein KSRP promotes the biogenesis of a subset of microRNAs. Nature 459:1010-1014. doi:10.1038/nature08025

51. Zhang X, Wan G, Berger FG et al (2011) The ATM kinase induces microRNA biogenesis in the DNA damage response. Mol Cell. doi:10.1016/j.molcel.2011.01.020

52. Han C, Liu Y, Wan G et al (2014) The RNA-binding protein DDX1 promotes primary microRNA maturation and inhibits ovarian tumor progression. Cell Rep 8:1447-1460. doi:10.1016/j. celrep.2014.07.058

53. Briata P, Lin W-J, Giovarelli M et al (2012) PI3K/AKT signaling determines a dynamic switch between distinct KSRP functions favoring skeletal myogenesis. Cell Death Differ 19:478-487. doi:10.1038/cdd.2011.117

54. Ruggiero T, Trabucchi M, De Santa F et al (2009) LPS induces $\mathrm{KH}$-type splicing regulatory protein-dependent processing of microRNA-155 precursors in macrophages. FASEB J 23(9):2898-2908. doi:10.1096/fj.09-131342

55. Guil S, Cáceres JF (2007) The multifunctional RNA-binding protein hnRNP A1 is required for processing of miR-18a. Nat Struct Mol Biol 14:591-596. doi:10.1038/nsmb1250 
56. Michlewski G, Cáceres JF (2010) Antagonistic role of hnRNP A1 and KSRP in the regulation of let-7a biogenesis. Nat Struct Mol Biol 17:1011-1018. doi:10.1038/nsmb.1874

57. Rupaimoole R, Wu SY, Pradeep S et al (2014) Hypoxia-mediated downregulation of miRNA biogenesis promotes tumour progression. Nat Commun 5:5202. doi:10.1038/ncomms6202

58. Van Den Beucken T, Koch E, Chu K et al (2014) Hypoxia promotes stem cell phenotypes and poor prognosis through epigenetic regulation of DICER. Nat Commun 5:5203. doi:10.1038/ ncomms6203

59. Shen J, Xia W, Khotskaya YB et al (2013) EGFR modulates microRNA maturation in response to hypoxia through phosphorylation of AGO2. Nature 497:383-387. doi:10.1038/ nature 12080

60. Kozakowska M, Ciesla M, Stefanska A et al (2012) Heme oxygenase-1 inhibits myoblast differentiation by targeting myomirs. Antioxid Redox Signal 16:113-127. doi:10.1089/ars.2011.3964

61. Weitz SH, Gong M, Barr I et al (2014) Processing of microRNA primary transcripts requires heme in mammalian cells. Proc Natl Acad Sci 111(5):1861-1866. doi:10.1073/pnas.1309915111

62. Quick-Cleveland J, Jacob JP, Weitz SH et al (2014) The DGCR8 RNA-binding heme domain recognizes primary microRNAs by clamping the hairpin. Cell Rep. doi:10.1016/j.celrep.2014.05.013

63. Shen J, Xia W, Khotskaya YB et al (2013) EGFR modulates microRNA maturation in response to hypoxia through phosphorylation of AGO2. Nature 497(7449):383-387. doi:10.1038/ nature 12080

64. Zeng Y, Sankala H, Zhang X, Graves PR (2008) Phosphorylation of Argonaute 2 at serine- 387 facilitates its localization to processing bodies. Biochem J 413:429-436. doi:10.1042/ BJ20080599

65. Qi HH, Ongusaha PP, Myllyharju J et al (2008) Prolyl 4-hydroxylation regulates Argonaute 2 stability. Nature 455:421-424. doi:10.1038/nature07186

66. Wu C, So J, Davis-Dusenbery BN et al (2011) Hypoxia potentiates microRNA-mediated gene silencing through posttranslational modification of Argonaute2. Mol Cell Biol 31:47604774. doi:10.1128/MCB.05776-11

67. Leung AKL, Vyas S, Rood JE et al (2011) Poly(ADPRibose) regulates stress responses and microRNA activity in the cytoplasm. Mol Cell 42:489-499. doi:10.1016/j. molcel.2011.04.015

68. Seo GJ, Kincaid RP, Phanaksri T et al (2013) Reciprocal inhibition between intracellular antiviral signaling and the RNAi machinery in mammalian cells. Cell Host Microbe 14:435-445. doi:10.1016/j.chom.2013.09.002

69. Rusinova I, Forster S, Yu S et al (2013) INTERFEROME v2.0: an updated database of annotated interferon-regulated genes. Nucleic Acids Res 41:1040-1046. doi:10.1093/nar/gks1215

70. Pedersen IM, Cheng G, Wieland S et al (2009) Interferon modulation of cellular microRNAs as an antiviral mechanism. Nature 449(7164):919-922. doi:10.1038/nature06205

71. Jopling CL, Yi M, Lancaster AM et al (2005) Modulation of hepatitis C virus RNA abundance by a liver-specific MicroRNA. Science 309:1577-1581. doi:10.1126/science.1113329

72. Wiesen JL, Tomasi TB (2009) Dicer is regulated by cellular stresses and interferons. Mol Immunol 46:1222-1228. doi:10.1016/j.molimm.2008.11.012

73. Olejniczak M, Polak K, Galka-Marciniak P, Krzyzosiak WJ (2011) Recent advances in understanding of the immunological off-target effects of siRNA. Curr Gene Ther 11:532-543. doi:10.2174/156652311798192770

74. Kok KH, Ng MHJ, Ching YP, Jin DY (2007) Human TRBP and PACT directly interact with each other and associate with dicer to facilitate the production of small interfering RNA. J Biol Chem 282:17649-17657. doi:10.1074/jbc.M611768200

75. Daher A, Laraki G, Singh M et al (2009) TRBP control of PACTinduced phosphorylation of protein kinase $r$ is reversed by stress. Mol Cell Biol 29:254-265. doi:10.1128/MCB.01030-08

76. Singh M, Castillo D, Patel CV, Patel RC (2011) Stress-induced phosphorylation of PACT reduces its interaction with TRBP and leads to PKR activation. Biochemistry 50:4550-4560. doi:10.1021/bi200104h

77. Heyam A, Lagos D, Plevin M (2015) Dissecting the roles of TRBP and PACT in double-stranded RNA recognition and processing of noncoding RNAs. Wiley Interdiscip Rev RNA 6:271-289. doi:10.1002/wrna.1272

78. Haase AD, Jaskiewicz L, Zhang $\mathrm{H}$ et al (2005) TRBP, a regulator of cellular PKR and HIV-1 virus expression, interacts with Dicer and functions in RNA silencing. EMBO Rep 6:961-967. doi:10.1038/sj.embor.7400509

79. Koscianska E, Starega-Roslan J, Krzyzosiak WJ (2011) The role of dicer protein partners in the processing of microRNA precursors. PLoS One. doi:10.1371/journal.pone.0028548

80. Lee Y, Hur I, Park S-Y et al (2006) The role of PACT in the RNA silencing pathway. EMBO J 25:522-532. doi:10.1038/ sj.emboj.7600942

81. Wilson RC, Tambe A, Kidwell MA et al (2015) Dicer-TRBP complex formation ensures accurate mammalian MicroRNA biogenesis. Mol Cell 57:397-408. doi:10.1016/j.molcel.2014.11.030

82. Fukunaga R, Han BW, Hung JH et al (2012) Dicer partner proteins tune the length of mature miRNAs in flies and mammals. Cell 151:533-546. doi:10.1016/j.cell.2012.09.027

83. Lee HY, Zhou K, Smith AM et al (2013) Differential roles of human Dicer-binding proteins TRBP and PACT in small RNA processing. Nucleic Acids Res 41:6568-6576. doi:10.1093/nar/ gkt361

84. Kim Y, Yeo J, Lee JH et al (2014) Deletion of human tarbp2 reveals cellular microRNA targets and cell-cycle function of TRBP. Cell Rep. doi:10.1016/j.celrep.2014.09.039

85. Kok KH, Lui PY, Ng MHJ et al (2011) The double-stranded RNA-binding protein PACT functions as a cellular activator of RIG-I to facilitate innate antiviral response. Cell Host Microbe 9:299-309. doi:10.1016/j.chom.2011.03.007

86. Khan AA, Betel D, Miller ML et al (2009) Transfection of small RNAs globally perturbs gene regulation by endogenous microRNAs. Nat Biotechnol 27:549-555. doi:10.1038/nbt0709-671a

87. Olejniczak M, Urbanek MO, Jaworska E et al (2016) Sequencenon-specific effects generated by various types of RNA interference triggers. Biochim Biophys Acta Gene Regul Mech 1859:306-314. doi:10.1016/j.bbagrm.2015.11.005

88. Pepin G, Ferrand J, Honing K et al (2016) Cre-dependent DNA recombination activates a STING-dependent innate immune response. Nucleic Acids Res 44:5356-5364. doi:10.1093/nar/ gkw405

89. Yi R, Qin Y, Macara IG, Cullen BR (2003) Exportin-5 mediates the nuclear export of pre-microRNAs and short hairpin RNAs. Genes Dev 17:3011-3016. doi:10.1101/gad.1158803

90. Grimm D, Streetz KL, Jopling CL et al (2006) Fatality in mice due to oversaturation of cellular microRNA/short hairpin RNA pathways. Nature 441:537-541. doi:10.1038/nature04791

91. Wan G, Zhang X, Langley RR et al (2013) DNA-damageinduced nuclear export of precursor microRNAs is regulated by the ATM-AKT pathway. Cell Rep. doi:10.1016/j. celrep.2013.05.038

92. Xie M, Li M, Vilborg A et al (2013) Mammalian 5'-capped microRNA precursors that generate a single microRNA. Cell 155:1568-1580. doi:10.1016/j.cell.2013.11.027 
93. Shapiro JS, Schmid S, Aguado LC et al (2014) Drosha as an interferon-independent antiviral factor. Proc Natl Acad Sci USA 111:7108-7113. doi:10.1073/pnas.1319635111

94. Yang Q, Li W, She $\mathrm{H}$ et al (2015) Stress induces p38 MAPKmediated phosphorylation and inhibition of drosha-dependent cell survival. Mol Cell. doi:10.1016/j.molcel.2015.01.004

95. Eulalio A, Behm-Ansmant I, Schweizer D, Izaurralde E (2007) P-Body formation is a consequence, not the cause, of RNA-mediated gene silencing. Mol Cell Biol 27:3970-3981. doi:10.1128/ MCB.00128-07

96. Kedersha N, Anderson P (2007) Mammalian stress granules and processing bodies. Methods Enzymol 431:61-81. doi:10.1016/ S0076-6879(07)31005-7

97. Anderson P, Kedersha N (2009) RNA granules: post-transcriptional and epigenetic modulators of gene expression. Nat Rev Mol Cell Biol 10:430-436. doi:10.1038/nrm2694

98. Leung AKL, Calabrese JM, Sharp PA (2006) Quantitative analysis of Argonaute protein reveals microRNA-dependent localization to stress granules. Proc Natl Acad Sci USA 103:1812518130. doi:10.1073/pnas.0608845103

99. Yang W, Chendrimada TP, Wang Q et al (2006) Modulation of microRNA processing and expression through RNA editing by ADAR deaminases. Nat Struct Mol Biol 13:13-21. doi:10.1038/ nsmb1041

100. Liddicoat BJ, Chalk AM, Walkley CR (2016) ADAR1, inosine and the immune sensing system: distinguishing self from nonself. Wiley Interdiscip Rev RNA. doi:10.1002/wrna.1322

101. Scadden ADJ, O'Connell MA (2005) Cleavage of dsRNAs hyper-edited by ADARs occurs at preferred editing sites. Nucleic Acids Res 33:5954-5964. doi:10.1093/nar/gki909

102. Kawahara Y, Zinshteyn B, Chendrimada TP et al (2007) RNA editing of the microRNA-151 precursor blocks cleavage by the Dicer-TRBP complex. EMBO Rep 8:763-769. doi:10.1038/ sj.embor.7401011

103. Kawahara Y, Megraw M, Kreider E et al (2008) Frequency and fate of microRNA editing in human brain. Nucleic Acids Res 36:5270-5280. doi:10.1093/nar/gkn479

104. Nigita G, Acunzo M, Romano G et al (2016) MicroRNA editing in seed region aligns with cellular changes in hypoxic conditions. Nucleic Acids Res. doi:10.1093/nar/gkw532

105. Ota H, Sakurai M, Gupta R et al (2013) ADAR1 forms a complex with dicer to promote MicroRNA processing and RNAinduced gene silencing. Cell. doi:10.1016/j.cell.2013.03.024

106. Starega-Roslan J, Witkos TM, Galka-Marciniak P, Krzyzosiak WJ (2015) Sequence features of Drosha and Dicer cleavage sites affect the complexity of IsomiRs. Int J Mol Sci 16:8110 8127. doi:10.3390/ijms 16048110

107. Katoh T, Sakaguchi Y, Miyauchi K et al (2009) Selective stabilization of mammalian microRNAs by $3^{\prime}$ adenylation mediated by the cytoplasmic poly(A) polymerase GLD-2. Genes Dev 23:433-438. doi:10.1101/gad.1761509

108. Backes S, Shapiro JS, Sabin LR et al (2012) Degradation of host MicroRNAs by poxvirus poly(A) polymerase reveals terminal RNA methylation as a protective antiviral mechanism. Cell Host Microbe 12:200-210. doi:10.1016/j. chom.2012.05.019

109. Thornton JE, Du P, Jing L et al (2014) Selective microRNA uridylation by Zcchc6 (TUT7) and Zcchc11 (TUT4). Nucleic Acids Res 42:11777-11791. doi:10.1093/nar/gku805

110. Heo I, Joo C, Kim YK et al (2009) TUT4 in concert with Lin28 suppresses MicroRNA biogenesis through PreMicroRNA uridylation. Cell 138:696-708. doi:10.1016/j. cell.2009.08.002

111. Park JH, Shin S-Y, Shin C (2017) Non-canonical targets destabilize microRNAs in human Argonautes. Nucleic Acids Res 45:gkx029. doi:10.1093/nar/gkx029
112. Eulalio A, Schulte L, Vogel J (2012) The mammalian microRNA response to bacterial infections. RNA Biol 9:742-750. doi:10.4161/rna.20018

113. Maudet C, Mano M, Sunkavalli U et al (2014) Functional highthroughput screening identifies the miR-15 microRNA family as cellular restriction factors for Salmonella infection. Nat Commun 5:4718. doi:10.1038/ncomms5718

114. Salzman DW, Nakamura K, Nallur S et al (2016) miR-34 activity is modulated through $5^{\prime}$-end phosphorylation in response to DNA damage. Nat Commun 7:10954. doi:10.1038/ncomms10954

115. Perry VH, Cunningham C, Holmes C (2007) Systemic infections and inflammation affect chronic neurodegeneration. Nat Rev Immunol 7:161-167. doi:10.1038/nri2015

116. Olejniczak M, Urbanek MO, Krzyzosiak WJ (2015) The role of the immune system in triplet repeat expansion diseases. Mediat Inflamm. doi:10.1155/2015/873860

117. Hoss AG, Lagomarsino VN, Frank S et al (2015) Study of plasma-derived miRNAs mimic differences in Huntington's disease brain. Mov Disord 30:1961-1964. doi:10.1002/mds.26457

118. Gaughwin PM, Ciesla M, Lahiri N et al (2011) Hsa-miR-34b is a plasma-stable microRNA that is elevated in pre-manifest Huntington's disease. Hum Mol Genet 20:2225-2237. doi:10.1093/ $\mathrm{hmg} / \mathrm{ddr} 111$

119. Müller M, Kuiperij HB, Claassen JA et al (2014) MicroRNAs in Alzheimer's disease: differential expression in hippocampus and cell-free cerebrospinal fluid. Neurobiol Aging 35:152-158. doi:10.1016/j.neurobiolaging.2013.07.005

120. Hara N, Kikuchi M, Miyashita A et al (2017) Serum microRNA miR-501-3p as a potential biomarker related to the progression of Alzheimer's disease. Acta Neuropathol Commun 5:10. doi:10.1186/s40478-017-0414-z

121. De Felice B, Annunziata A, Fiorentino G et al (2014) miR$338-3 p$ is over-expressed in blood, CFS, serum and spinal cord from sporadic amyotrophic lateral sclerosis patients. Neurogenetics 15:243-253. doi:10.1007/s10048-014-0420-2

122. de Andrade HMT, de Albuquerque M, Avansini SH et al (2016) MicroRNAs-424 and 206 are potential prognostic markers in spinal onset amyotrophic lateral sclerosis. J Neurol Sci 368:19-24. doi:10.1016/j.jns.2016.06.046

123. Packer AN, Xing Y, Harper SQ et al (2008) The bifunctional microRNA miR-9/miR-9* regulates REST and CoREST and is downregulated in Huntington's disease. J Neurosci 28:1434114346. doi:10.1523/JNEUROSCI.2390-08.2008

124. Hébert SS, Horré K, Nicolaï L et al (2008) Loss of microRNA cluster miR-29a/b-1 in sporadic Alzheimer's disease correlates with increased BACE1/beta-secretase expression. Proc Natl Acad Sci USA 105:6415-6420. doi:10.1073/pnas.0710263105

125. Lukiw WJ (2007) Micro-RNA speciation in fetal, adult and Alzheimer's disease hippocampus. NeuroReport 18:297-300. doi:10.1097/WNR.0b013e3280148e8b

126. Johnson R, Zuccato C, Belyaev ND et al (2008) A microRNAbased gene dysregulation pathway in Huntington's disease. Neurobiol Dis 29:438-445. doi:10.1016/j.nbd.2007.11.001

127. Roshan R, Shridhar S, Sarangdhar MA et al (2014) Brain-specific knockdown of miR-29 results in neuronal cell death and ataxia in mice. RNA 20:1287-1297. doi:10.1261/rna.044008.113

128. Wang X, Liu P, Zhu H et al (2009) miR-34a, a microRNA upregulated in a double transgenic mouse model of Alzheimer's disease, inhibits bcl2 translation. Brain Res Bull 80:268-273. doi:10.1016/j.brainresbull.2009.08.006

129. Bak M, Silahtaroglu A, Møller M et al (2008) MicroRNA expression in the adult mouse central nervous system. RNA 14:432444. doi:10.1261/rna.783108

130. Li X, Khanna A, Li N, Wang E (2011) Circulatory mir-34a as an RNA-based, noninvasive biomarker for brain aging. Aging (Albany NY) 3:985-1002 
131. Lee SKS-T, Chu K, Im W-S et al (2011) Altered microRNA regulation in Huntington's disease models. Exp Neurol 227:172179. doi:10.1016/j.expneurol.2010.10.012

132. Miñones-Moyano E, Porta S, Escaramís G et al (2011) MicroRNA profiling of Parkinson's disease brains identifies early downregulation of miR-34b/c which modulate mitochondrial function. Hum Mol Genet 20:3067-3078. doi:10.1093/hmg/ ddr210

133. Zovoilis A, Agbemenyah HY, Agis-Balboa RC et al (2011) microRNA-34c is a novel target to treat dementias. EMBO J 30:4299-4308. doi:10.1038/emboj.2011.327

134. Wang W-X, Huang Q, Hu Y et al (2011) Patterns of microRNA expression in normal and early Alzheimer's disease human temporal cortex: white matter versus gray matter. Acta Neuropathol 121:193-205. doi:10.1007/s00401-010-0756-0

135. Parisi C, Napoli G, Amadio S et al (2016) MicroRNA-125b regulates microglia activation and motor neuron death in ALS. Cell Death Differ 23:1-11. doi:10.1038/cdd.2015.153

136. Russell AP, Wada S, Vergani L et al (2013) Disruption of skeletal muscle mitochondrial network genes and miRNAs in amyotrophic lateral sclerosis. Neurobiol Dis 49:107-117. doi:10.1016/j.nbd.2012.08.015

137. Lau P, Bossers K, Janky R et al (2013) Alteration of the microRNA network during the progression of Alzheimer's disease. EMBO Mol Med 5:1613-1634. doi:10.1002/emmm.201201974

138. Lungu G, Stoica G, Ambrus A (2013) MicroRNA profiling and the role of microRNA-132 in neurodegeneration using a rat model. Neurosci Lett 553:153-158. doi:10.1016/j. neulet.2013.08.001

139. Zhou Y, Lu M, Du R-H et al (2016) MicroRNA-7 targets Nodlike receptor protein 3 inflammasome to modulate neuroinflammation in the pathogenesis of Parkinson's disease. Mol Neurodegener 11:28. doi:10.1186/s13024-016-0094-3

140. Junn E, Lee K-W, Jeong BS et al (2009) Repression of alpha-synuclein expression and toxicity by microRNA-7. Proc Natl Acad Sci USA 106:13052-13057. doi:10.1073/ pnas.0906277106

141. Williams AH, Valdez G, Moresi V et al (2009) MicroRNA-206 delays ALS progression and promotes regeneration of neuromuscular synapses in mice. Science 326:1549-1554. doi:10.1126/ science. 1181046

142. Li YY, Cui JG, Hill JM et al (2011) Increased expression of miRNA-146a in Alzheimer's disease transgenic mouse models. Neurosci Lett 487:94-98. doi:10.1016/j.neulet.2010.09.079

143. Pogue AI, Li YY, Cui J-G et al (2009) Characterization of an NF-kappaB-regulated, miRNA-146a-mediated down-regulation of complement factor $\mathrm{H}(\mathrm{CFH})$ in metal-sulfate-stressed human brain cells. J Inorg Biochem 103:1591-1595. doi:10.1016/j. jinorgbio.2009.05.012

144. Lukiw WJ, Zhao Y, Jian GC (2008) An NF-kB-sensitive micro RNA-146a-mediated inflammatory circuit in alzheimer disease and in stressed human brain cells. J Biol Chem 283:3131531322. doi:10.1074/jbc.M805371200

145. Wu Q, Ye X, Xiong Y et al (2016) The protective role of microRNA-200c in Alzheimer's disease pathologies is induced by beta amyloid-triggered endoplasmic reticulum stress. Front Mol Neurosci. doi:10.3389/fnmol.2016.00140

146. Boissonneault V, Plante I, Rivest S, Provost P (2008) MicroRNA-298 and microRNA-328 regulate expression of mouse beta -amyloid precursor protein converting enzyme 1. J Biol Chem. doi:10.1074/jbc.M807530200

147. Persengiev S, Kondova I, Otting N et al (2011) Genome-wide analysis of miRNA expression reveals a potential role for miR144 in brain aging and spinocerebellar ataxia pathogenesis. Neurobiol Aging. doi:10.1016/j.neurobiolaging.2010.03.014
148. Braak H, Braak E (2000) Pathoanatomy of Parkinson's disease. J Neurol 247(Suppl):II3-I10. doi:10.1007/PL00007758

149. Kim J, Inoue K, Ishii J et al (2007) A MicroRNA feedback circuit in midbrain dopamine neurons. Science 317:1220-1224. doi:10.1126/science.1140481

150. De Mena L, Coto E, Cardo LF et al (2010) Analysis of the micro-RNA-133 and PITX3 genes in Parkinson's disease. Am J Med Genet Part B Neuropsychiatr Genet 153:1234-1239. doi:10.1002/ajmg.b.31086

151. Liu Y, Liao S, Quan H et al (2016) Involvement of microRNA-135a-5p in the protective effects of hydrogen sulfide against Parkinson's disease. Cell Physiol Biochem 40:18-26. doi: $10.1159 / 000452521$

152. Wang G, van der Walt JM, Mayhew G et al (2008) Variation in the miRNA-433 binding site of FGF20 confers risk for Parkinson disease by overexpression of $\alpha$-synuclein. Am J Hum Genet 82:283-289. doi:10.1016/j.ajhg.2007.09.021

153. Hoss AG, Labadorf A, Beach TG et al (2016) microRNA profiles in Parkinson's disease prefrontal cortex. Front Aging Neurosci. doi:10.3389/fnagi.2016.00036

154. Liu W, Liu C, Zhu J et al (2012) MicroRNA-16 targets amyloid precursor protein to potentially modulate Alzheimer's-associated pathogenesis in SAMP8 mice. Neurobiol Aging 33:522-534. doi:10.1016/j.neurobiolaging.2010.04.034

155. Prasad KN (2017) Oxidative stress and pro-inflammatory cytokines may act as one of the signals for regulating microRNAs expression in Alzheimer's disease. Mech Ageing Dev 162:63-71. doi:10.1016/j.mad.2016.12.003

156. Fang M, Wang J, Zhang X et al (2012) The miR-124 regulates the expression of BACE1/beta-secretase correlated with cell death in Alzheimer's disease. Toxicol Lett 209:94-105. doi:10.1016/j.toxlet.2011.11.032

157. Liang $\mathrm{C}, \mathrm{Zhu} \mathrm{H}, \mathrm{Xu} \mathrm{Y}$ et al (2012) MicroRNA-153 negatively regulates the expression of amyloid precursor protein and amyloid precursor-like protein 2. Brain Res 1455:103-113. doi:10.1016/j.brainres.2011.10.051

158. Zhu HC, Wang LM, Wang $M$ et al (2012) MicroRNA-195 downregulates Alzheimer's disease amyloid- $\beta$ production by targeting BACE1. Brain Res Bull 88:596-601. doi:10.1016/j. brainresbull.2012.05.018

159. Long JM, Ray B, Lahiri DK (2012) MicroRNA-153 physiologically inhibits expression of amyloid- $\beta$ precursor protein in cultured human fetal brain cells and is dysregulated in a subset of Alzheimer disease patients. J Biol Chem 287:31298-31310. doi:10.1074/jbc.M112.366336

160. Hebert SS, Horre K, Nicolai L et al (2009) MicroRNA regulation of Alzheimer's Amyloid precursor protein expression. Neurobiol Dis 33:422-428. doi:10.1016/j.nbd.2008.11.009

161. Wang W-X, Rajeev BW, Stromberg AJ et al (2008) The expression of microRNA miR-107 decreases early in Alzheimer's disease and may accelerate disease progression through regulation of beta-site amyloid precursor protein-cleaving enzyme 1. J Neurosci 28:1213-1223. doi:10.1523/JNEUROSCI.5065-07.2008

162. Bhatnagar S, Chertkow H, Schipper HM et al (2014) Increased microRNA-34c abundance in Alzheimer's disease circulating blood plasma. Front Mol Neurosci 7:2. doi:10.3389/ fnmol.2014.00002

163. Kabaria S, Choi DC, Chaudhuri AD et al (2015) Inhibition of miR-34b and miR-34c enhances $\alpha$-synuclein expression in Parkinson's disease. FEBS Lett 589:319-325. doi:10.1016/j. febslet.2014.12.014

164. Ponomarev ED, Veremeyko T, Barteneva $\mathrm{N}$ et al (2011) MicroRNA-124 promotes microglia quiescence and suppresses EAE by deactivating macrophages via the C/EBP- $\alpha-P U .1$ pathway. Nat Med 17:64-70. doi:10.1038/nm.2266 
165. Li YR, King OD, Shorter J, Gitler AD (2013) Stress granules as crucibles of ALS pathogenesis. J Cell Biol 201:361-372. doi:10.1083/jcb.201302044

166. Aulas A, Vande Velde C (2015) Alterations in stress granule dynamics driven by TDP-43 and FUS: a link to pathological inclusions in ALS? Front Cell Neurosci 9:423. doi:10.3389/ fncel.2015.00423
167. Kawahara Y, Mieda-Sato A (2012) TDP-43 promotes microRNA biogenesis as a component of the Drosha and Dicer complexes. PNAS 109:3347-3352. doi:10.1073/pnas.1112427109

168. Haramati S, Chapnik E, Sztainberg Y et al (2010) miRNA malfunction causes spinal motor neuron disease. Proc Natl Acad Sci 107:13111-13116. doi:10.1073/pnas.1006151107 